Check for updates

London

Cite this as: $B M J$ 2021;373:n1626 http://dx.doi.org/10.1136/bmj.n1626 Published: 24 June 2021

\title{
Covid-19: Third of people infected have long term symptoms
}

\section{Adrian O'Dowd}

Around a third of people in England who developed covid-19 went on to experience long term symptoms sometimes called "long covid," a UK study has found and experts believe that more than two million people could have been affected in this way.

Findings from the React-2 (Real-time Assessment of Community Transmission) study from Imperial College London used self-reported data from 508707 adults aged 18 or older who took part in three rounds of surveys that were carried out between September 2020 and February 2021, in which they were asked about 29 different symptoms.

The study, published as a preprint and not yet peer reviewed, ${ }^{1}$ found that around a fifth (19.2\%) of those surveyed reported having had contracted covid-19 previously, with more than a third $(37.7 \%)$ reporting at least one persistent symptom and $14.8 \%$ experiencing three or more symptoms lasting at least 12 weeks.

Almost a third of people (30.5\%) with at least one symptom lasting 12 weeks or more reported having had severe covid-19 symptoms that had a "significant effect on my daily life" at the time of their illness.

Overall, $5.8 \%$ of the study population had one or more persistent symptoms for 12 weeks or more, a proportion that could translate to more than two million people in England. The most common persistent symptoms included tiredness, shortness of breath, muscle aches, and difficulty sleeping.

In addition, the researchers found that long covid was more common among women than men (1.5 times as likely) and in people who were overweight or obese, who smoked, lived in deprived areas, or had been admitted to hospital. In contrast, persistent covid-19 symptoms were lower in people of Asian ethnicity.

The findings also indicated that prevalence of persistent symptoms increased with age, with a 3.5\% increase in likelihood for each decade of life.

At a press briefing to launch the study, Paul Elliott, director of the REACT programme and chair in epidemiology and public health medicine at Imperial, was asked how long "long" covid may be for some people.

"For some people, I think they will have very long term consequences of having had the infection," said Elliott. "There are certainly people who have got organ damage, so if they have that they will continue to have the consequences.

"Long covid is still poorly understood, but we hope through our research that we can contribute to better identification and management of this condition, which our data and others' suggest may ultimately affect millions of people in the UK alone."
The authors suggested various possible reasons why women seemed to be more likely to have long covid symptoms. Fellow report author Helen Ward, professor of public health at Imperial, told The BMJ, "There are a lot of theories. It may be that it is to do with a more active immune response in women that reduces symptoms initially but then produces prolonged symptoms.”

After the briefing the government said that covid-19 was still a relatively new disease and that it was providing scientists with €5om (€6om; \$7om) of research funding to better understand its long term effects.

Similar themes to the React-2 study's findings emerged in another study, led by researchers at University College London and King's College London. ${ }^{2}$ It found that a sixth $(17 \%)$ of middle aged people who reported being infected with SARS-CoV-2 also reported long covid symptoms but that this proportion fell to $7.8 \%$ in younger adults.

Whitaker M, Elliott J, Chadeau-Hyam M, et al. Persistent symptoms following SARS-CoV-2 infection in a random community sample of 508707 people. Imperial College London. 24 Jun. https://spiral.imperial.ac.uk/handle/10044/1/89844.

2 Thompson EJ, Williams DM, Walker AJ, et al. Risk factors for ongoing symptomatic COVID-19 and post-COVID-19 syndrome: analyses of 10 longitudinal studies and electronic health records in the UK. 24 Jun. https://www.ucl.ac.uk/covid-19-longitudinal-health-wellbeing/researchoutputs/preprints.

This article is made freely available for use in accordance with BMJ's website terms and conditions for the duration of the covid-19 pandemic or until otherwise determined by BMJ. You may use, download and print the article for any lawful, non-commercial purpose (including text and data mining) provided that all copyright notices and trade marks are retained. 